\title{
Blood Transfusion Safety among Blood Donors and Recipients in Minna - North-Central Nigeria, 2014
}

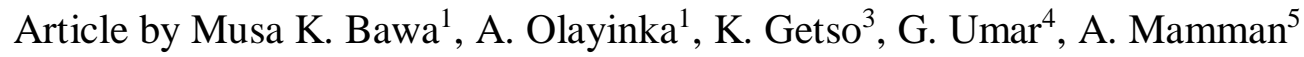 \\ ${ }^{1,2,3}$ Nigerian Field Epidemiology and Laboratory Training Program (NFELTP), Abuja-Nigeria \\ ${ }^{3}$ Ministry of health, Kano, Kano State, Nigeria \\ ${ }^{4}$ United Nations Children Education Fund (UNICEF), Kano, Nigeria \\ ${ }^{5}$ Haematology Department, Ahmadu Bello University, Shika, Zaria \\ E-mail: musabawa56@yahoo.com
}

\begin{abstract}
Background: Transfusion usually is a life-saving therapeutic intervention, however many preventable errors may make it hazardous for donors or recipients. Ensuring supply of safe blood is a key intervention in reducing mortality and morbidity attributable to blood transfusion. We conducted a descriptive, cosssectional study among blood donors to assess blood donor safety in Minna, north-Central Nigeria.

Methods: We recruited consecutively, all consenting, HIV, hepatitis $B$ and $C$ and anaemia screened blood donors between September, 2013 and January, 2014. We screened all subjects for haematological indices using a haematological analyzer (Abacus analyzer 2.75, Diatron ${ }^{\circledR}$ U.S.A) respectively. We administered structured questionnaires to obtain socio-demographic and socio-economic characteristics and practices. Data was subjected to descriptive statistical analyses using Epi Info version 3.5.4. Significant associations were presumed if $p<0.05$.

Results: A total of 345 subjects were recruited, 336 (97.4\%) males. Mean age \pm SD was $32.4 \pm 8.5$ years. Monthly earnings ranged from $\$ 109$ to $\$ 212$ 136(40.6\%). The majority of the blood donors 195 (55.9\%) were anaemic ( $P C V<36, \mathrm{Hb}<12 \mathrm{~g} / \mathrm{dl}), 158(81.0 \%)$ of which were for purpose of family replacement. Strata of the blood donors were family replacement 274 (79.4), voluntary 60 (17.4), commercial interest 11 $(3.2 \%)$.

Conclusions: The blood donor safety is low in Minna. Majority of the blood donors were anaemic. The quality of routine donor screening for anaemia should be improved.
\end{abstract}

Keywords: Anaemia, Transfusion, Blood donors, Safety, Nigeria.

\section{Introduction}

Transfusion is usually a lifesaving therapeutic intervention, however many preventable errors may make this a hazardous procedure [1]. The WHO recommends that blood donation should in all cases be absolutely voluntary 2,3]. However, in Nigeria, voluntary donors are relatively scarce, hence family replacement and commercial donors have become alternative sources of blood $[4,5]$. Healthy persons who are between the ages of 18 and 65 years with haemoglobin $(\mathrm{Hb})$ levels of not less than $13.5 \mathrm{~g} / \mathrm{dl}$ in males or $12.5 \mathrm{~g} / \mathrm{dl}$ in females are acceptable as donors if they test negative for transfusion transmissible infections which include $\mathrm{HBV}, \mathrm{HCV}$, HIV, malaria, syphilis, Chagas disease. However, females are only accepted as donors if they are not pregnant or breast-feeding [6].

The provision of well-preserved cellular or plasma components of blood with predictable effects and uncommon severe side effects has become so developed that research and development efforts are advancing at a tremendous pace. This has permitted sophisticated surgery, chemotherapy, organ and bone marrow transplant. However, blood transfusion is still associated with complications such as infections, metabolic overload and immune reactions. The African region of the World Health Organization (WHO), fraught with high disease burden including the high prevalence of HIV/AIDS, Hepatitis B and C and malaria; poor economies; and a lack of resources for blood transfusion in the face of poorly developed 
DOI: $10.21522 / \mathrm{TIJPH} .2013 .05 .04 . A r t 038$

ISSN: $2520-3134$

health infrastructure, faces unique challenges to blood safety. The trends and status of the regional strategy for blood safety for Africa was reviewed using 1999 to 2006 data from the Global Database on Blood Safety (GDBS). An estimated 529,500 mothers died in the world in the year 2000 of which 247,000 died in Africa south of the Sahara. Moreover, it is estimated that the lifetime risk of death of mothers of childbearing age is 1:16 in sub-Saharan Africa compared with 1: 2,800 in the developed world. Africa has one of the highest maternal mortality ratios in the world standing at 920/100,000 live births compared to 20/100,000 live births in the developed world. Twenty five to 40 percent of maternal deaths are due to haemorrhage.

Most studies on blood donors are centered on the selective evaluation of red blood cell parameters with little or no regard to white blood cells and platelets. A study by Jeremiah revealed, of the blood donors studied, $18.8 \%$ were found to be anemic (packed cell volume $[\mathrm{PCV}]<33 \%$ ) while $12.5 \%$ were leucopenic (white blood cell [WBC] count <2.0 $\times 10(9) / \mathrm{L}$ ) [7]. Anaemia accounts for $5 \%$ of donor deferrals in Nigeria [8]. There is the need to determine the blood donor safety. We conducted a descriptive, coss-sectional study among blood donors to assess blood donor safety in Minna, north-Central Nigeria. This study will further provide bases for the implementation of donor safety strategies in health care service delivery.

\section{Methods}

\section{Study area}

The study was conducted in Minna, the capital city of Niger State, Nigeria. Minna is located in the North Central region of Nigeria. ${ }^{54}$ Minna city is made up of two LGAs, each having one secondary health facility which are General Hospital (GH), Minna and Ibrahim Babangida Specialist hospital (IBBSH), Minna located in Minna South and Minna East LGAs respectively. The average annual blood donor rates are 3865, 756 for GH, Minna and IBBSH, Minna respectively and the population of the city is 304,113 as at $2007^{54}$ census. Screening for anaemia is part of blood transfusion screening algorithm in Minna. Malaria is endemic in Minna ${ }^{53}$ and anaemia is a common diagnosis.

\section{Study design}

This is a hospital based cross-sectional study with both descriptive and analytical components. The descriptive component described the blood donors and their haematological profiles in terms of person, place and time while the analytical component identified the factors associated with anaemia among the blood donors.

\section{Study population}

The study population was all potential blood donors that presented at the identified blood donation centers, GH Minna and IBBSH, Minna in Minna town, Niger State.

\section{Inclusion criteria}

- Healthy looking persons who were between the ages of 18 and 65 years with haemoglobin $(\mathrm{Hb})$ levels of not less than $13.5 \mathrm{~g} / \mathrm{dl}$ in males or $12.5 \mathrm{~g} / \mathrm{dl}$ in females.

- Those already screened for transmission transmissible infections and found illegible to donate.

\section{Exclusion criteria}

Those that low $\mathrm{Hb}$ and PCV and tested positive for HIV, HBV and HCV.

\section{Sample size determination}

A total of 345 blood donors were recruited into the study. The sample size was obtained using the formula as follows:

$\mathrm{n}=\frac{\mathrm{Z} \alpha^{2} \mathrm{pq}}{\mathrm{d}^{2}}$

Where: 
$\mathrm{n}=$ required sample size

$\mathrm{z}={ }_{(1-a / 2)}=1.96=$ value of the standard distribution corresponding to a significance level of $\alpha$ (1.96 for a 2-sided test at the 0.05 level)

$\mathrm{p}=\mathrm{CMV}$ prevalence among prospective blood donors at a tertiary health facility (JUTH) in Jos, Nigeria $=92 \%(0.92)^{8}$

$\mathrm{q}=1-\mathrm{p}(1-0.92)=0.08$

$\mathrm{d}=$ absolute precision $=3 \%(0.03)$

$\mathrm{n}=\frac{1.96^{2} \times 0.92 \times 0.08}{0.032}=314$

$0.03^{2}$

$10 \%$ non-response $=31$

Therefore, $\mathrm{n}=345$

\section{Sampling technique}

Minna town is made up of two LGAs, Minna West and Minna East, each made up of one secondary health facility (HF), GH, Minna and IBBSH, Minna. The study population was 1540 obtained from blood donor registers of the two HFs over a given period of time. The blood donor registers of each of the two HFs were reviewed for the number of past blood donors for a period of one year. Each was divided by 3 to obtain average blood donor number for a period of four months, same length of period for which the participants were going to be recruited. Sampling frames were obtained as 1288 and 252 (5:1) for GH, Minna and IBBSH, Minna respectively. Proportionate allocation of the participants for the HFs was done given 289 and 56 for GH, Minna and IBBSH, Minna respectively. Blood donors were systematically selected from the two HFs after obtaining an interval for selection for each, using $n / N=K$. The first participant was selected randomly by balloting between 1 and $\mathrm{K}$, and then thereafter every Kth blood donor recruited until the required sample was obtained.

\section{Study instruments}

We used laboratory forms for capturing laboratory data, and interviewer-administered questionnaires made up of introduction, demography, risk factor sections were used for capturing data on sociodemographic, socio-economic characteristics and practices of the participants.

\section{Data collection methods}

The blood donors were screened for CMV antibodies, IgM and IgG using blood samples collected. Blood samples, $5 \mathrm{mls}$ each for serum and whole blood was collected using plain and EDTA vacuntainers respectively. The serum was used for CMV ELISA screening for CMV antibodies i.e. IgG and IgM using ELISA kit (DIALAB ${ }^{\circledR}$ Austria) [9], while the whole blood was analyzed for haematological indices using a haematological analyzer (Abacus junior haematology analyzer 2.75, manufactured in 1995 by Diatron ${ }^{\circledR}$ U.S.A). Interviewer administered questionnaire was employed to obtain information from participants regarding their socio-demographic, socio-economic characteristics and practices. Four research assistants were recruited and trained for the study.

\section{Analysis for haematological indices}

Blood samples for haematological analyses were analysed daily within 12 hours of collection using a haematological analyzer (Abacus junior haematology analyzer 2.75, manufacture in 1995 by Diatron ${ }^{\circledR}$ U.S.A). The analysis were done at General Hospital Minna for Hb, PCV, MCH, MCHC, WBC, RBC, MCV, neutrophils, lymphocytes, MIE (monocyte, eosinophil, basophil), platelet count, and mean cell distribution width (MCDW), mean platelet distribution width (MPDW). The procedure included:

1. Using the EDTA blood container, whole blood was inserted into the analyzer.

2. The analyser aspirated 2 micro liters of the blood into the probe and autoanalysed.

3. The result appeared on the screen and copied. 
DOI: $10.21522 /$ TIJPH.2013.05.04.Art038

ISSN: $2520-3134$

\section{Quantitative method}

Interviewer administered questionnaire method was employed using structured questionnaires (appendix 3). The questionnaires were pretested at a nearby HF, General Hospital Bida, Niger State to ascertain their flexibility and acceptability. Each participant was administered a questionnaire to obtain information regarding age, sex, occupation, ethnic group, marital status, past history of transfusion and other sociodemographic, socio-economic and practices. ${ }^{12}$

\section{Data management}

The independent variables were the socio-demographic and socio-economic characteristics of the respondents, cultural practices, while the dependent variable was the CMV serological status of the blood donors regarding $\mathrm{IgM}$ and $\mathrm{IgG}$, which are either positive or negative.

We reviewed all the completed questionnaires before electronic entry. Data obtained were analyzed using Epi Info version 3.5.4 (US Centers for Disease Control and Prevention) and Microsoft Excel 2007. The chi-square test was used to evaluate the statistical significance of associations. Significant associations were presumed if $\mathrm{p}<0.05$.

Ethical Considerations: Ethical clearance was obtained from the GH, Minna, and IBBSH, Minna research, and ethical clearance committees. Respect to participants' rights was observed including the right to refuse participation with explanation through participant's information form and provision of individual consent forms for the consent of the participants.

\section{Limitations}

Private health facilities in Minna city constituted some percentage of blood donors but could not be considered in this study as their inclusion could have constituted bias as most of them were not consistent blood donation centers. Preliminary findings revealed that their exclusion may not affect the representativeness of the study.

\section{Results}

The majority of the blood donors, $139(40.3 \%)$ were aged 20-29 years, $230(66.7 \%)$ were married, 65 $(19.5 \%)$ were unemployed, 273 (79.4\%) were family blood donors. Most, 146 (42.6\%) had post-secondary education, and $136(40.6 \%)$ had a monthly income of between $\$ 18000$ and $\$ 35000$ (Table 1).

Of the blood donors, $55.9 \%$ were anaemic (HCT<36\%), 53.3\% low $\mathrm{Hb}, 63.0 \% \mathrm{MCH}$, while $76.5 \%$ had normal WBC, 55.4\% normal RBC, 81.6\% normal platelet count (Table 2).

The pattern of $\mathrm{Hb}$ and PCV among various strata of blood donors as they relate to their $\mathrm{Hb}$ and PCV level showed $56.5 \%$ have PCV below the normal range and family replacement blood donors form the majority, $158(81.0 \%)$ of the total (195) anaemic (PCV<36\%) blood donors. None of the blood donors had $\mathrm{Hb}$ or PCV above normal range (Table 3 ).

PCV was found to be significantly correlated with $\mathrm{Hb}(\mathrm{P}<0.001)$. Other haeamatological indices all respectively showed positive correlation with $\mathrm{Hb}$ and $\mathrm{WBC}$ except $\mathrm{MCHC}$ and PCV which showed no correlation with $\mathrm{Hb}$ and WBC respectively, but were all not statistically significant (Table 4).

\section{Discussion}

Our study found many of the blood donors in this study, 55.9\% were found to be anaemic (PCV <36\%). The study participants were considered to have been screened (laboratory screening) for anaemia with PCV cutoffs as not less than $40.5 \%(13.5 \mathrm{~g} / \mathrm{dl})$ in males or $37.5 \%(12.5 \mathrm{~g} / \mathrm{dl})$ in females based on the blood donor eligibility criteria of the country. Yet, such a high level of proportion of anaemic blood donors was found. This goes to show the level of the quality issues associated with screening procedures. The high proportion of anaemia in our study corroborates findings of other studies which include studies in Port Harcourt, Nigeria and south India. This is also identical with findings of $\mathrm{Xu}$ and colleagues, Gordon-smith and associates and Taglietti and colleagues [10 - 12]. This high level of anaemia may be associated with the 
finding in the study that $81.5 \%$ of the anaemic donors were family replacement donors and family replacement donors constituted $79.4 \%$ of all the donors (345) in the study.

We found slight difference in demographics between blood donors at GH Minna and those at IBBSH. We had $97.6 \%$ of the blood donors as males at GH Minna and $96.4 \%$ at IBBSH. Majority of the blood donors at GH Minna were aged 30-39 against 20-29 years at IBBSH. This shows some remarkable difference in the demographic of the two recruitment sites.

Our study found family replacement donors constituted the majority, $79.4 \%$ while commercial donors made up $3.2 \%$ and voluntary donors $17.4 \%$. The low proportion of voluntary donors reflects the duo of ignorance and low national development index [2]. Family replacement blood donation predominates in the absence of a well-organized national voluntary blood donation programme. People then rely on family or friends of patients to act as replacement donors. However, research findings indicates that blood from family or replacement donor is found to be unsuitable more often than blood from voluntary non enumerated and therefore presents a potentially greater risk to the safety of the blood supply [13-14].

The commonest age group in this study was 20-29 years; this is higher than 18-20 years reported by a study in Chennai, India [15]. Our finding showed an overwhelming male predominance (97.4\%). It is comparable to $95.4 \%$ reported by Akinbami and colleagues [16]. It may be linked to the belief that women do not donate blood because of menstrual flow, pregnancy and childbearing[17].

We found that most study participants were employed, retirees accounted for very few. It shows blood donation is an activity of persons $<65$ years of age [2]. The majority of the blood donors were educated as those without education were $21.9 \%$. The rate of illiteracy observed in our study is higher than $15.4 \%$ reported for the North-Central zone in the National Demographic and Health Survey (NDHS) 2008 by National Population Commission, Nigeria (NPC) [18].

The findings of our study cannot be generalized to Nigeria as the study was a health facility-based study. Also, most of the private health facilities were not consistent blood donation centers and therefore were not considered in the study as their inclusion could have constituted a bias. Our findings will still provide the basis for the implementation of donor safety strategies in Minna.

\section{Conclusions}

We conclude that we observed the majority of the blood donors were anaemic. Prospective blood donors for immunocompromised patients, however, should be screened for CMV. The quality of screening for anemia should be improved.

\section{Acknowledgements}

We wish to acknowledge Professors Kabir Sabitu, Gabrielle Poggensee (Nigerian Field Epidemiology and Laboratory Training Program (NFELTP), professor Elizeus Rutebemberwa (Makerere University) for their mentoring support in this work. I want to acknowledge my NFELTP field supervisor Dr Tijjani Hussein.

We also acknowledge the contributions of Alhaji Alfa Dangana and Dr. James Kolo (Niger State Ministry of Health) for their technical support. We acknowledge the cooperation of the staff of haematology department, GH, Minna and antiretroviral therapy (ART) (President Emergency Plan for AID's Relief PEPFAR) laboratory, ABUTH, Zaria for enabling us haematological and serological analysis. We also acknowledge the contributions of the research assistants, Abdullahi Habibu, Abdullahi Sanusi of GH, Minna and Yusuf Ahmadu of IBBSH, Minna.

\section{References}

[1]. Abdel Messih AY, Ismail MA, Saad AA AM. The degree of safety of family replacement donors versus voluntary non-remunerated donors in an Egyptian population: a comparative study. Blood Transfus. 2014;12(2):15966.

[2]. Adediran IA, Fesogun RB, Oyekunle AA. Haematological parameters in prospective Nigerian blood donors rejected on account of anaemia and/or microfilaria infestation. Nigerian Journal of Medicine 2005; 14: 45-50 
DOI: $10.21522 / \mathrm{TIJPH} .2013 .05 .04 . A r t 038$

ISSN: $2520-3134$

[3]. Alao OO, Joseph DE, Mamman A, Banwat EB. The Seroprevalence of cytomegalovirus antibodies among prospective blood donors in Jos. Nigerian Journal of Medicine, National Association of Resident Doctors of Nigeria 2009; 17(2):200-202.

[4]. Ahmad MM, Terri K, Faustine EN, Kenra F. Maternal mortality: A consideration for developing countries and emergency preparedness blood safety plan. Afr Sang 2008; 11(2):5.

[5]. Ahmed SG, Ibrahim UA, Hassan AW. Adequacy and pattern of blood donations in northeast Nigeria: the implications for blood safety. Annals of Tropical Medicine and Parasitology 2007; 101: 725-731.

[6]. Barret CL, Pretorius L, Jata AD. New opportunity for transfusion training for African nurses: Development of a distance based blood transfusion short learning program. Afri Sang 2011; 14:1.

[7]. Egbewale EE, Ogunro PS, Muhibi MA. Knowledge, attitude and practice of blood donation in south west Nigeria. Nigerian Hospital Practice 2008; 2: 132-136.

[8]. Federal Ministry of Health. The Nigerian National Blood Policy. Nigeria, Abuja, 2006.

[9]. Hamdan HZ, Abdelbagi IE, Nasser NM AI. Seroprevalence of cytomegalovirus and rubella among pregnant women in western Sudan. Virol J. 2011;11(8):217.

[10]. Jeremiah ZA, Umoh RE, Adias TC (2011).Subclinical leukopenia in a cross section of Nigerian blood donors. $J$ Blood Med. 2011; 2:79-85.

[11]. JM H. Child bearing practices in northern Nigeria. Ibadan Univ Press. 1972;1:5-11.

[12]. Madauci IH, Isah Y DB. Hausa customs. North Niger Publ Co. 1992;1:12.

[13]. National Population Commission (NPC) FR of N. National Demographic and Health Survey (NDHS). CCF Macro Calvert. 2008;33.

[14]. Seferi I, Xhumari P BG. Prevalence of cytomegalovirus in paid and unpaid blood donor population in Tirana. Int J Heal Sci. 2009;2(4):261.

[15]. Taglietti F, Drapeau CM, Grilli E, Capone A, Noto P TS et al. Hemolytic anemia due to acute cytomegalovirus infection in an immunocompetent adult: a case report and review of the literature. J Med Case Rep. 2010;4:334.

[16]. World Health Organization. Resolutions, Recommendations and Decisions. League of Red Cross and Red Crescent Societies. Geneva, 1984.

[17]. Xu L-H, Fang J-P, Weng W-J, Huang K, Guo H-X, Liu Y et al. Pure red cell aplasia associated with cytomegalovirus and Epstein-Barr virus infection in seven cases of Chinese children. Hematology. 2013;18(1):56-9.

\section{Tables and figures}

Table 1. Sociodemographic characteristics of blood donors in minna-nigeria, 2014

\begin{tabular}{|l|l|l|}
\hline Variable & Frequency $(\mathbf{N}=\mathbf{3 4 5})$ & Percent $(\%)$ \\
\hline Age & & \\
\hline$<20$ & 6 & 1.7 \\
$20-29$ & 139 & 40.3 \\
$30-39$ & 137 & 39.7 \\
$40-49$ & 46 & 13.3 \\
$50-59$ & 14 & 4.1 \\
$\geq 60$ & 3 & 0.9 \\
\hline Marital Status & & \\
\hline Married & 230 & 66.7 \\
Single & 113 & 32.8 \\
Separated & 2 & 0.6 \\
\hline Occupation & & \\
\hline
\end{tabular}




\begin{tabular}{|c|c|c|}
\hline $\begin{array}{l}\text { Self employed } \\
\text { Employed } \\
\text { Student } \\
\text { Unemployed } \\
\text { Retired }\end{array}$ & $\begin{array}{l}183 \\
95 \\
59 \\
6 \\
2\end{array}$ & $\begin{array}{l}53.0 \\
27.5 \\
17.1 \\
1.7 \\
0.6\end{array}$ \\
\hline \multicolumn{3}{|c|}{ Monthly income level } \\
\hline $\begin{array}{l}\text { Above } \$ 120000 \\
\$ 70000 \text { - } \$ 20000 \\
\$ 35000 \text {-Below } \\
\$ 70000 \\
\$ 18000 \text {-Below } \\
\$ 35000 \\
\text { Below } \$ 18000\end{array}$ & $\begin{array}{l}3 \\
16 \\
91 \\
136 \\
89\end{array}$ & $\begin{array}{l}0.9 \\
4.8 \\
27.2 \\
40.6 \\
26.6\end{array}$ \\
\hline
\end{tabular}

Table 2. Pattern of haematological indices among blood donors in Minna, North Central Nigeria

\begin{tabular}{llll}
\hline Variable & Low (\%) & High (\%) & Normal (\%) \\
\hline Hb & $177(53.3)$ & $45(13.6)$ & $110(33.1)$ \\
PCV & $185(55.7)$ & $1(0.3)$ & $146(44.0)$ \\
WBC total & $32(9.6)$ & $46(13.9)$ & $254(76.5)$ \\
Lymphocyte & $98(29.6)$ & $119(35.8)$ & $115(34.6)$ \\
Granulocyte & $114(34.3)$ & $46(13.9)$ & $172(51.8)$ \\
MIE (Mono, & $160(48.2)$ & $90(27.1)$ & $82(24.7)$ \\
Eosino, Bas) & $80(24.1)$ & $68(20.5)$ & $184(55.4)$ \\
RBC & $209(63.0)$ & $1(0.3)$ & $122(36.7)$ \\
MCH & $3(0.9)$ & $10(3.0)$ & $319(96.1)$ \\
MCHC & $29(8.8)$ & $32(9.6)$ & $271(81.6)$ \\
PLT & $0(0.0)$ & $231(69.6)$ & $101(30.4)$ \\
RCDW & $110(33.3)$ & $0(0.0)$ & $221(66.7)$ \\
MPV & $78(23.5)$ & $1(0.3)$ & $253(76.2)$ \\
MCV & & & \\
\hline
\end{tabular}

NB-Values of normal ranges

WBC-5-10 (10\%/L), Lymphocyte count- 25-40 (\%), Granulocyte count- 50-75 (\%), MIE- 3-7 (\%), RBC4-5 (10 $12 / \mathrm{L})$, HB- 12-17.4 (g/dl), HCT- 36-52 (\%), MCV- 76-96 (fl), MCH- 27-32 (g/dl), MCHC-30-35 $(\mathrm{g} / \mathrm{dl})$, PLT- 150-400 (10 $/ \mathrm{L})$, RDWC- 11.5-14.5 (\%), MPV- 8-15 (fl)

Table 3. Pattern of $\mathrm{Hb}$ and $\mathrm{PCV}$ among various strata of blood donors in minna, north central nigeria

\begin{tabular}{llllll}
\hline Category & \multirow{2}{*}{$\begin{array}{l}\text { Type of blood } \\
\text { donor }\end{array}$} & \multicolumn{3}{l}{ Parameters } & \multicolumn{3}{l}{ PCV } \\
\cline { 3 - 6 } & & Hb & Percentage & Frequency & Percentage \\
\cline { 3 - 6 } & Commercial & 8 & 3.5 & 6 & 3.1 \\
Low & Family & 185 & 85.5 & 158 & 81.0 \\
& Voluntary & 34 & 15.0 & 31 & $15 . .9$ \\
\multirow{4}{*}{ Normal } & Commercial & 3 & 2.5 & 5 & 3.3 \\
& Family & 89 & 75.4 & 116 & 77.4 \\
& Voluntary & 26 & 22.0 & 29 & 22.0 \\
High & Commercial & 0 & 0 & 0 & 0 \\
& Family & 0 & 0 & 0 & 0 \\
& Voluntary & 0 & 0 & 0 & 0 \\
\hline
\end{tabular}


DOI: $10.21522 / \mathrm{TIJPH} .2013 .05 .04 . A r t 038$

ISSN: $2520-3134$

NB-Values of normal ranges

$\mathrm{Hb}=12-17.4 \mathrm{~g} / \mathrm{dl}, \mathrm{PCV}=36-52 \%$. Hb-Low=<12g/dl,Normal=12-17.4g/dl, High=>17.g/dl.

PCV- Low $=<36 \%$, Normal $=36-52 \%$, High $=>52 \%$

Table 4. Correlation relationship between haematological indices of blood donors in Minna, North Central Nigeria

\begin{tabular}{lll}
\hline Variables & $\begin{array}{l}\text { Correlation } \\
\text { coefficient }\left(\mathbf{r}^{\wedge} \mathbf{2}\right)\end{array}$ & P-value \\
\hline Hb and MCH & 0.24 & 0.19 \\
Hb and PCV & $\mathbf{0 . 8 5}$ & $\mathbf{< . 0 0 1}$ \\
Hb and WBC & 0.06 & 0.53 \\
Hb and Lymph & 0.12 & 0.38 \\
Hb and Neutrophil & 0.16 & 0.30 \\
Hb and MCV & 0.01 & 0.76 \\
Hb and MCHC & 0.00 & 0.88 \\
Hb and MCDW & 0.16 & 0.20 \\
WBC and Lymph & 0.36 & 0.09 \\
WBC and Neutrophil & 0.24 & 0.19 \\
WBC and MIE & 0.07 & 0.48 \\
WBC and PCV & 0.00 & 0.91 \\
WBC and MCHC & 0.32 & 0.12 \\
WBC and PLT & 0.19 & 0.25 \\
WBC and Age & 0.13 & 0.30 \\
\hline
\end{tabular}

